\title{
The assessment of biomarkers in sentinel cattle for monitoring vanadium exposure
}

\author{
B. Gummow, ${ }^{* a}$ J. van den Broek, ${ }^{b}$ W. F. A. Kirsten, ${ }^{c}$ C. J. Botha, ${ }^{a}$ \\ J. P. T. M. Noordhuizen ${ }^{b}$ and J. A. P. Heesterbeek ${ }^{b}$ \\ Received 30th September 2005, Accepted 15th February 2006 \\ First published as an Advance Article on the web 9th March 2006 \\ DOI: $10.1039 / \mathbf{b 5 1 3 8 6 0 d}$
}

Various potential biomarkers were sampled for vanadium every 3-4 months from Bos indicus beef cattle farmed extensively immediately adjacent (high exposure (HE) group) and two km away (low exposure (LE) group) from a vanadium processing plant, respectively. Vanadium intake (mg vanadium $\mathrm{kg}^{-1}$ bwt $\mathrm{d}^{-1}$ ) was modelled using environmental and physiological data as inputs. The vanadium intake ranged from 0.57 to $5.44 \mathrm{mg}$ vanadium $\mathrm{kg}^{-1}$ bwt $\mathrm{d}^{-1}$ in the HE group and 0.41 to $2.61 \mathrm{mg}$ vanadium $\mathrm{kg}^{-1}$ bwt $\mathrm{d}^{-1}$ in the LE group over a five-year period of monitoring.

Samples collected from live sentinel animals over the five-year period included caudal coccygeal vertebrae, tail-switch hair, milk, urine, faeces, rib-bone biopsies and a wide range of blood clinical pathology and haematological parameters. The data was analysed for differences in response between the HE and LE groups. Where differences were found, a linear mixed-effects regression model was fitted to model the relationship between the exposure dose and the response variable. The model included the effects of age, duration of exposure and response, and allowed the prediction of the exposure dose given these inputs. Moreover, forty-two adult cattle were slaughtered over the five years. A wide range of tissue samples, rumen content and whole blood were taken from the cattle at slaughter for vanadium determination. In live animals, a difference in response was found between the HE group and LE group with respect to serum albumin $(n=36)$, monocyte $(n=36)$ and thrombocyte $(n=36)$ counts, and hair $(n=2)$ and faeces ( $n=34)$ vanadium concentrations. No difference in vanadium concentrations could be shown for urine $(n=36)$, the traditional occupational health biomarker. Regression models are described for serum albumin, monocyte counts, faeces and hair, which showed the most promise as biomarkers. Average concentrations of vanadium in the tissues of slaughtered cattle ranged from 0.08 to $2.94 \mathrm{mg} \mathrm{kg}^{-1}$ (wet-weight basis) and rumen content contained $16.67 \mathrm{mg} \mathrm{kg}^{-1}$. Significant correlations were found between the exposure dose (end-dose) just prior to slaughter and the concentrations of vanadium in the coccygeal vertebrae, liver, diaphragm and rib-bone in descending order of magnitude. Other tissues showed poor correlation to the end-dose. Tissue levels of vanadium in healthy cattle include a much wider range than is currently reflected in the literature. The best tissue from slaughter animals for assessing chronic vanadium exposure is probably the liver.

\section{Introduction}

Biomarkers, biological markers and biologic markers are for all practical purposes equivalent terms. ${ }^{1}$ However, a distinction is currently arising through common usage between these terms and the term biomonitoring. Biomonitoring is tending to be equated with residue analysis because residue analysis (detection of parent compound or metabolite in tissue, fluid or breath) is considered by some to be chemical dosimetry and a measure of body burden. ${ }^{1}$ For the purposes of this paper, a

\footnotetext{
${ }^{a}$ Faculty of Veterinary Science, University of Pretoria, Pvt. Bag X04, Onderstepoort, 0110, South Africa. E-mail:

Bruce.Gummow@up.ac.za; Fax: +2712 5298315; Tel: +2712 5298257

${ }^{b}$ Faculty of Veterinary Medicine, University of Utrecht, Yalelaan 7 , 3584 CL Utrecht, Netherlands

${ }^{c}$ Institute for Soil, Climate and Water, P. Bag X79, Pretoria, 0001, South Africa
}

biomarker is defined as any measurable chemical, biochemical, physiological, cytological, morphological, or other biological response obtainable from tissues, fluids or expired gasses that is associated directly or indirectly with exposure to an environmental pollutant, ${ }^{2,3}$ and therefore includes biomonitoring. Biomarkers can be used to either determine the exposure to the causative agent, to predict adverse health effects or as a measure of susceptibility. Furthermore, biomarkers can be used as surrogates for or in combination with other measures of exposure.

In the vanadium industry the most common biomarker used in occupational health is urine concentrations of vanadium ${ }^{4-8}$ and a green discolouration of the tongue, ${ }^{6}$ the latter resulting from the direct accumulation of high doses of vanadium pentoxide. Urine concentration of vanadium has never been an ideal biomarker due to the wide variability in results and a better, preferably non-invasive, biomarker is needed by the 
industry. Concentrations of minerals in tissues are also frequently used by veterinarians as biomarkers to make a diagnosis of exposure in cases of toxicity, and environmentalists are known to use tissue mineral levels as indicators of environmental pollution. This paper discusses the usefulness of various potential biomarkers in cattle sentinels that were monitored over a five-year period. It also looks at tissue concentrations of vanadium in slaughtered animals and their usefulness as a monitoring and diagnostic tool for public health authorities, environmentalists and veterinarians.

\section{Materials and methods}

\section{Experimental design}

A cohort study was carried out using an initial cohort of thirty Bos indicus beef cattle of the same approximate mass. They were purchased in 1999 as heifers and randomly divided into two groups; a high exposure (HE) group of ten and a low exposure (LE) group of twenty cattle. The HE group was farmed in an area immediately adjacent to a vanadium mine where high background concentrations of vanadium occurred $\left(\bar{x}=1229 \mathrm{mg} \mathrm{V} \mathrm{d}^{-1}\right)$. The LE group was farmed approximately $2-3 \mathrm{~km}$ from the first group in an area where exposure was roughly half that of the $\mathrm{HE}$ group $\left(\bar{x}=532 \mathrm{mg} \mathrm{V} \mathrm{d}^{-1}\right)$. Both groups were farmed as an extensive beef cattle enterprise with the resultant heifer offspring used as replacements or additions to the herd over the five-year period. Bull calves were slaughtered between $18 \mathrm{~m}$ and $24 \mathrm{~m}$ of age. Bulls used for breeding were fertility tested Bonsmara bulls, hired for the breeding season from various independent farmers. Separate bulls were used for the HE and LE camps. The herd size was limited by the amount of available grazing and a stocking density of approximately 1 animal per 5 ha was used as a guideline. The area where cattle grazed was bushveld and comprised a number of grass species; the predominant ones being Aristida congesta, Panicum maximum, Themeda triandra, Heteropogon contortus, Eragrostis rigidior and a Urochloa species. The only supplemental feeding provided was a commercial winter lick and baled lucern (fed at $1 \%$ body weight $\mathrm{d}^{-1}$ ), which was fed for approximately 2-3 months during mid-winter (July-September), when the grazing was insufficient to sustain the animals.

\section{Observations and analytical procedures}

The farm was visited by at least one of the veterinary coworkers once every 3-4 months, to monitor the health status of the herd, collect samples and update records. A record system was kept by the Department of Production Animal Studies at the Faculty of Veterinary Science, University of Pretoria for analysis purposes.

Various potential biomarkers were collected every 3-4 months from the cattle and evaluated as indicators of vanadium exposure. These included the most caudal ossified coccygeal vertebra (tail-bone), hair from the tail-switch, milk from lactating cows, naturally voided urine and faeces from the rectum. Two years into the trial, once 2-3 caudal coccygeal vertebrae had been removed from the original cows, it was decided for ethical reasons to take rib-biopsies to enable bone sampling from these animals to continue. Rib-biopsies were taken from the last rib approximately $1 / 3$ of the way down and the piece of bone removed was approximately $1 \mathrm{~cm}$ in diameter by $0.5 \mathrm{~cm}$ deep. Vanadium analysis of tissues and milk was done by the Agricultural Research Institute, Institute for Soil, Climate and Water (ISCW) using atomic emission spectrometry (ICP-AES) according to internationally accepted methods and quality control procedures. ${ }^{9-11}$

In addition to the tissue samples and body fluids, a serum and whole blood (EDTA) sample was collected from the jugular vein of sentinel cattle to examine haematological and clinical chemistry parameters. The haematology parameters monitored were: haemoglobin concentration $(\mathrm{Hb})$, red cell count (RCC), heamatocrit (Ht), mean corpuscular volume (MCV), mean corpuscular haemoglobin concentration (MCHC), red cell distribution width (RDW), white cell count (WCC), mature neutrophils ( $\mathrm{N}$ mat.), immature neutrophils (N imm.), lymphocytes, monocytes, eosinophils, basophils and thrombocyte count ( $\mathrm{Thr} \mathrm{C}$ ). The clinical chemistry parameters monitored were: total serum protein (TSP), albumin (Alb), globulin (Glob), the albumin:globulin ratio (AG), the alphaglobulin fraction ( $\alpha$-glob), beta-globulin fraction ( $\beta$-glob), the gamma-globulin fraction ( $\gamma$-glob), gamma-glutamyltransferase (GGT), aspartate aminotransferase (AST), creatine phosphokinase (CK) activities and blood urea nitrogen (BUN) and blood creatinine (Creat) concentrations. Enzyme activities and serum protein, urea and creatinine concentrations were analyzed using an automated chemical analyser (Technicon RAXT system, Miles Inc., Diagnostics Division, Tarrytown, New York) and the manufacturer's methods and reagents. Complete blood counts were determined using a Cell-dyne 3700 (Abbott Laboratories, South Africa). Electrophoresis was performed with a Beckman Model R-100 Microzone Electrophoresis System (Econoscan, Helena Laboratories). All haematological and clinical chemistry analysis was performed by the Clinical Pathology Laboratory, Faculty of Veterinary Science, University of Pretoria.

At the same time as samples were collected from the cattle, grass, soil, and aerial fall-out samples were collected at 18 sampling points along nine transects within the camps for determination of vanadium concentrations. These inputs together with drinking water vanadium concentrations were then used in an exposure dose model described by Gummow et al. ${ }^{12,32}$ to model the dose of vanadium taken in by the cattle (in $\mathrm{mg} \mathrm{kg}^{-1} \mathrm{~d}^{-1}$ ). The exposure dose includes intake of vanadium by both the oral and inhalation routes.

During the five-year period of monitoring, non-productive cows or bull calves were slaughtered annually at a nearby abattoir. Six cohorts of animals were slaughtered over the fiveyear period on the following dates; 25-Aug-99, 09-Feb-01, 06Mar-01, 31-May-02, 20-Jun-03, 07-May-04. A total of 42 cattle were slaughtered over this period (Table 6). All animals underwent the same slaughter process routinely carried out at the abattoir, with the exception that tissue samples were taken from the carcasses as they moved along the slaughter line. Each carcass was inspected by two veterinarians from the Faculty of Veterinary Science, University of Pretoria as well the abattoir's meat inspector for lesions or abnormalities. Specific tissues were taken for analysis of vanadium 
Table 1 Clinical chemistry parameter means and 95\% confidence limits for the difference in means of high exposure (HE) and low exposure (LE) South African sentinel cattle (1999-2004) ${ }^{a b}$

\begin{tabular}{|c|c|c|c|c|c|}
\hline \multirow[b]{2}{*}{ Biomarker } & \multirow[b]{2}{*}{ Normal range } & \multicolumn{2}{|l|}{ Mean } & \multirow[b]{2}{*}{$95 \% \mathrm{LCL}$} & \multirow[b]{2}{*}{$95 \%$ UCL } \\
\hline & & HE group & LE group & & \\
\hline $\mathrm{TSP} / \mathrm{g} \mathrm{l}^{-1}$ & $65-78$ & 74.33 & 74.88 & -2.47 & 1.37 \\
\hline $\mathrm{Alb} / \mathrm{g} \mathrm{l}^{-1}$ & $28-37$ & 30.68 & 32.07 & -2.59 & -0.19 \\
\hline Glob/g $1^{-1}$ & $28-42$ & 44.01 & 43.14 & -1.01 & 2.75 \\
\hline $\mathrm{AG}$ & $0.61-1.18$ & 0.71 & 0.76 & $-\mathbf{0 . 1 0}$ & -0.004 \\
\hline$\alpha-$ glob $/ \mathrm{g}^{-1}$ & $10-13.5$ & 11.83 & 11.54 & -1.13 & 1.72 \\
\hline$\beta$-glob/g ${ }^{-1}$ & $8.3-10.3$ & 15.33 & 14.90 & -2.27 & 3.12 \\
\hline$\gamma$-glob/g $1^{-1}$ & $13-42$ & 15.08 & 14.80 & -3.01 & 3.58 \\
\hline $\mathrm{AST} / \mathrm{U}^{-1}$ & $10-80$ & 30.66 & 31.61 & -2.96 & 1.06 \\
\hline $\mathrm{CK} / \mathrm{U}^{-1}$ & $5-60$ & 98.04 & 92.19 & -13.69 & 25.40 \\
\hline $\mathrm{GGT} / \mathrm{U} \mathrm{l}^{-1}$ & $0-25$ & 15.91 & 11.06 & -1.23 & 10.92 \\
\hline $\mathrm{BUN} / \mathrm{mmol} \mathrm{l}^{-1}$ & $3.6-10.7$ & 4.52 & 4.30 & -0.53 & 0.97 \\
\hline Creat $/ \mu \mathrm{mol} 1^{-1}$ & $10-133$ & 122.69 & 124.75 & -14.06 & 9.94 \\
\hline
\end{tabular}

concentrations and for histopathology. Tissues taken for vanadium analysis were approximately $5 \mathrm{~cm}^{3}$ in size where possible and were stored in a deep freezer at $-18{ }^{\circ} \mathrm{C}$ prior to analysis. Analysis was carried out within 3 months of the collection of samples.

The following tissues were taken for vanadium analysis from animals slaughtered: the most caudal ossified coccygeal vertebra (tail-bone), rib-bone, rib-bone biopsy, Musculus iliopsoas (fillet muscle), Musculus triceps brachii (triceps muscle), Pars costalis (diaphragmatic muscle), cerebellum, cerebrum, lung (cranial lobe), liver (right lobe), kidney, mesenteric lymphnode, spleen, rumen content, testes and whole blood. The rib biopsy was a $1 \mathrm{~cm}$ diameter $\times 0.5 \mathrm{~cm}$ deep punch of bone taken from the dorsal lateral aspect of the last rib-bone.

\section{Data analysis}

The results were analysed using Microsoft Excel (version 2000) and the statistical packages NCSS $2004^{13}$ and R 2.1.1. ${ }^{14}$ The data collected covered a five-year period of monitoring.

Live animals. Data collected from live animals for each sample period comprised selected animals from all generations on the farm at that time. Live animals were sampled twentyfour times over the five-year period. On each occasion between six and twenty-nine cattle were sampled per experimental group with an average sample size of twelve per group. The variation in sample size was because animals from successive generations were added to the numbers as the trial progressed.

The data was tested for normality and equal variance using NCSS 2004. ${ }^{13}$ The assumption of normality and equal variance could not be met for all biomarker response variables so it was decided to treat the data as non-parametric data for the purposes of comparison. Differences between the HE and LE groups with respect to biomarker response were assessed by means of confidence intervals (Tables 1, 2 and 3); where a difference in response was apparent, the data from the HE and LE groups was pooled and a linear mixed-effect model was used to model the relationship between the exposure dose and the biomarker response (Table 5). The model was defined as: mean-exposure-dose (exp-dose) = age group (age) + duration-of-exposure (time-to-bleed) + age $\times$ biomarker-responseat-bleed (response). The model included random animal effects because the observations on the same animal are correlated and random time to bleed because these correlations depend

Table 2 Haematology parameter means and 95\% confidence limits for the difference in means of high exposure (HE) and low exposure (LE) South African sentinel cattle (1999-2004) ${ }^{a b}$

\begin{tabular}{|c|c|c|c|c|c|}
\hline \multirow[b]{2}{*}{ Biomarker } & \multirow[b]{2}{*}{ Normal ranges } & \multicolumn{2}{|l|}{ Mean } & \multirow[b]{2}{*}{$95 \% \mathrm{LCL}$} & \multirow[b]{2}{*}{$95 \%$ UCL } \\
\hline & & HE group & LE group & & \\
\hline $\mathrm{Hb} / \mathrm{g} \mathrm{l}^{-1}$ & $80-140$ & 124.98 & 123.69 & -3.06 & 5.64 \\
\hline $\mathrm{RCC} / 10^{12} 1^{-1}$ & $5-9$ & 8.52 & 8.57 & -0.34 & 0.24 \\
\hline $\mathrm{Ht} / 11^{-1}$ & $0.24-0.4$ & 0.38 & 0.38 & -0.01 & 0.01 \\
\hline $\mathrm{MCV} / \mathrm{fl}$ & $40-60$ & 44.53 & 44.15 & -1.84 & 2.60 \\
\hline $\mathrm{MCHC} / \mathrm{g} \mathrm{dl}^{-1}$ & $30-36$ & 33.08 & 32.89 & -0.51 & 0.89 \\
\hline RDW (\%) & $19.5-27$ & 24.63 & 24.05 & -0.56 & 1.63 \\
\hline $\mathrm{WCC} / 10^{9} 1^{-1}$ & $4-10$ & 12.04 & 11.41 & -0.63 & 1.88 \\
\hline $\mathrm{N}$ mat. $/ 10^{9} 1^{-1}$ & $0.6-4$ & 3.60 & 2.90 & -0.15 & 1.56 \\
\hline $\mathrm{N}$ imm. $/ 10^{9} 1^{-1}$ & $0-0.12$ & 0.06 & 0.03 & -0.04 & 0.10 \\
\hline Lymph $/ 10^{9} 1^{-1}$ & $2.5-7.5$ & 6.99 & 7.18 & -1.00 & 0.63 \\
\hline Mono $/ 10^{9} 1^{-1}$ & $0.03-0.84$ & 0.70 & 0.56 & 0.04 & 0.24 \\
\hline Eos $/ 10^{9} 1^{-1}$ & $0-2.4$ & 0.70 & 0.67 & -0.13 & 0.18 \\
\hline Baso $/ 10^{9} 1^{-1}$ & $0-0.2$ & 0.05 & 0.05 & -0.03 & 0.02 \\
\hline Thr C $/ 10^{9} 1^{-1}$ & $200-600$ & 443.22 & 295.14 & 8.56 & 287.59 \\
\hline
\end{tabular}


Table 3 Tissue and body fluid ( $\mathrm{mg} \mathrm{kg}^{-1}$ wet-weight) means and $95 \%$ confidence limits for the difference in means of the HE and LE South African sentinel cattle for (1999-2004) ${ }^{a b}$

\begin{tabular}{|c|c|c|c|c|c|}
\hline \multirow[b]{2}{*}{ Biomarker } & \multirow[b]{2}{*}{ No. per group } & \multicolumn{2}{|l|}{ Mean } & \multirow[b]{2}{*}{$95 \% \mathrm{LCL}$} & \multirow[b]{2}{*}{$95 \%$ UCL } \\
\hline & & HE group & LE group & & \\
\hline Hair & 6 & 57.67 & 38.33 & $-4.26 \times 10^{-5}$ & 38.67 \\
\hline Urine & 18 & 247.89 & 335.22 & -308.61 & 133.94 \\
\hline Faeces & 19 & 29.72 & 18.45 & 0.82 & 21.71 \\
\hline Milk & 15 & 0.42 & 0.37 & -0.26 & 0.36 \\
\hline Tail-bone & 15 & 1.76 & 1.00 & -0.55 & 2.08 \\
\hline Rib-biopsy & 6 & 2.00 & 1.16 & -0.23 & 1.91 \\
\hline
\end{tabular}

on time. This was the starting model. Then the same model was fitted without the interaction: exp-dose $=$ age + time-tobleed + response and Akaike's information criterion (AIC) was compared with that of the starting model. If the AIC was smaller, then this model was used in the same procedure for the fixed effects. The final model was the one with the lowest AIC. The residuals of this final model were checked with a plot of the residuals vs. the fitted values and a quantile-quantile (qq-plot) graph. The age groups used in the model were: (1) 0-6 m old, (2) 7-12 m old, (3) 13-18 m old and (4) > $18 \mathrm{~m}$ old. The age groups were based on previous findings that suggested responses may be related to these age groups. ${ }^{15}$

Slaughter animals. Data from slaughter animals was first analysed descriptively to establish the concentrations of vanadium in sampled bovine tissues. A range of possible values that could be expected for each tissue was then modelled using @ Risk version 4.5.2 (Palisade Corporation, USA) and a lognormal distribution function. The lognormal distribution function for each set of tissue concentrations was defined using the data fitting software Bestfit version 4.5.2 (Palisade corporation, USA). A lognormal distribution function was used because it is a distribution function commonly used to describe environmental data ${ }^{16}$ and because it consistently fitted the raw data well.

To check for differences in vanadium concentrations between the various tissues, the Kruskal-Wallis $Z$ multiple comparison test was used. ${ }^{17}$ This test uses a distribution-free multiple comparison, meaning that the assumption of normality is not necessary. It is used for testing pairs of medians following the Kruskall-Wallis test. The Bonferroni $z$-value $(z>2.39)$ was used for assessing significance, which is a $z$-value that has been adjusted for multiple tests.

Slaughter data was analysed for correlations between the independent predictor variables given below and the tissue vanadium concentrations, and between the various tissues with respect to vanadium concentrations. The Spearman-rank test was used to evaluate correlations. ${ }^{13}$

The predictor variables were:

(1) The length of time the animal had been exposed to vanadium, based on the number of days from when the animal entered the trial or was born until slaughter.

(2) The median dose of vanadium that the animal had been exposed to during the trial (median dose). This was modelled using the method described by Gummow et al. ${ }^{12}$ It was possible from the available environmental data to model the

Table 4 Model outputs for dose of vanadium $\left(\mathrm{mg} \mathrm{V} \mathrm{kg}^{-1} \mathrm{bwt} \mathrm{d}^{-1}\right)$ taken in by South African sentinel cattle in the HE and the LE groups at the time of each sample taking over the five-year period of the trial. Bold numbers indicate exposure doses corresponding to the slaughter cattle and time when they were slaughtered (end-dose)

\begin{tabular}{|c|c|c|c|c|c|c|c|c|c|c|}
\hline \multirow[b]{3}{*}{ Date } & \multicolumn{5}{|c|}{ Low exposure camps } & \multicolumn{5}{|c|}{ High exposure camps } \\
\hline & \multirow[b]{2}{*}{ Min } & \multicolumn{3}{|c|}{ Percentiles } & \multirow[b]{2}{*}{ Max } & \multirow[b]{2}{*}{ Min } & \multicolumn{3}{|c|}{ Percentiles } & \multirow[b]{2}{*}{$\operatorname{Max}$} \\
\hline & & 5 th & 50 th & 95th & & & 5 th & 50 th & 95th & \\
\hline 15-Jul-99 & 0.22 & 0.53 & 1.18 & 2.45 & 6.36 & 0.43 & 0.73 & 1.47 & 3.04 & 7.92 \\
\hline 10-Nov-99 & 0.33 & 0.8 & 1.68 & 3.32 & 7.61 & 0.23 & 0.91 & 2.74 & 7.81 & 27.94 \\
\hline 23-Feb-00 & 0.04 & 0.15 & 0.37 & 0.89 & 2.26 & 0.06 & 0.19 & 0.49 & 1.27 & 3.66 \\
\hline 30-May-00 & 0.17 & 0.39 & 0.89 & 1.75 & 4.45 & 0.25 & 0.72 & 1.71 & 3.69 & 9.78 \\
\hline 23-Aug-00 & 0.27 & 0.65 & 1.52 & 3.15 & 7.07 & 0.58 & 1.4 & 3.34 & 7.28 & 20.7 \\
\hline 2-Nov-00 & 0.12 & 0.25 & 0.6 & 1.28 & 2.33 & 0.27 & 0.94 & 2.55 & 5.8 & 10 \\
\hline 5-Mar-01 & 0.17 & 0.55 & 1.2 & 2.34 & 4.72 & 0.17 & 0.84 & 2.73 & 8.55 & 35.87 \\
\hline 20-Jun-01 & 0.44 & 1.09 & 2.45 & 5.04 & 9.87 & 1.55 & 2.64 & 5.2 & 9.44 & 18.45 \\
\hline 31-Jan-02 & 0.1 & 0.28 & 0.64 & 1.39 & 3.31 & 0.2 & 0.53 & 1.2 & 2.53 & 5.62 \\
\hline 17-Apr-02 & 0.16 & 0.41 & 0.88 & 1.77 & 4.35 & 0.14 & 0.51 & 1.44 & 4.08 & 12.49 \\
\hline 24-Aug-02 & 0.25 & 0.72 & 1.65 & 3.4 & 7.78 & 0.25 & 1.04 & 3.37 & 10.64 & 70.44 \\
\hline 01-Oct-02 & 0.21 & 0.62 & 1.71 & 4.39 & 14.27 & 0.32 & 0.91 & 2.1 & 4.65 & 11.1 \\
\hline 23-Jan-03 & 0.07 & 0.25 & 0.66 & 1.64 & 4.74 & 0.15 & 0.44 & 1.21 & 3.03 & 10.85 \\
\hline 23-Apr-03 & 0.12 & 0.31 & 0.75 & 1.76 & 6.92 & 0.08 & 0.34 & 0.96 & 2.65 & 10.43 \\
\hline 23-Jul-03 & 0.29 & 0.85 & 2.02 & 4.66 & 15.44 & 0.21 & 1.1 & 4.07 & 14.89 & 71.39 \\
\hline 29-Oct-03 & 0.38 & 0.84 & 1.72 & 3.26 & 6.17 & 1.09 & 1.71 & 3.23 & 5.12 & 6.23 \\
\hline 24-Jan-04 & 0.07 & 0.23 & 0.68 & 1.97 & 9.9 & 0.08 & 0.25 & 0.69 & 1.92 & 9.47 \\
\hline 21-Apr-04 & 0.1 & 0.25 & 0.55 & 1.12 & 2.18 & 0.19 & 0.52 & 1.19 & 2.64 & 6.3 \\
\hline
\end{tabular}


Table 5 Linear mixed effects mean-exposure dose model for serum albumin, hair, faeces and monocyte counts of South African sentinel cattle, 1999-2004

\begin{tabular}{|c|c|c|c|c|c|}
\hline & $95 \% \mathrm{LCL}$ & Value & $95 \% \mathrm{UCL}$ & $t$-value & $p$-value \\
\hline \multicolumn{6}{|c|}{ Albumin } \\
\hline \multicolumn{6}{|c|}{ Exp-dose $\sim$ age $2+$ age $3+$ age $4+$ time-to-bleed + response } \\
\hline (Intercept) & 2.10 & 2.88 & 3.67 & 7.20 & 0.00 \\
\hline \multicolumn{6}{|l|}{ Factor (age) } \\
\hline Age 2 & -0.89 & -0.47 & -0.055 & -2.21 & 0.03 \\
\hline Age 3 & -0.17 & 0.29 & 0.74 & 1.24 & 0.21 \\
\hline Age 4 & -0.74 & -0.33 & 0.075 & -1.59 & 0.11 \\
\hline Time-to-bleed & -0.00 & -0.00 & 0.00 & -1.09 & 0.28 \\
\hline Response & -0.05 & -0.03 & -0.01 & -2.55 & 0.01 \\
\hline \multicolumn{6}{|l|}{ Monocyte count } \\
\hline \multicolumn{6}{|c|}{ Exp-dose $\sim$ age $2+$ age $3+$ age $4+$ time-to-bleed + response } \\
\hline (Intercept) & 1.71 & 2.08 & 2.4 & 11.05 & 0.00 \\
\hline \multicolumn{6}{|l|}{ Factor (age) } \\
\hline Age 2 & -0.67 & -0.23 & 0.21 & -1.01 & 0.31 \\
\hline Age 3 & -0.10 & 0.37 & 0.84 & 1.53 & 0.13 \\
\hline Age 4 & -0.58 & -0.13 & 0.31 & -0.59 & 0.55 \\
\hline Time-to-bleed & -0.00 & -0.00 & 0.00 & -1.22 & 0.22 \\
\hline Response & -0.50 & -0.23 & 0.04 & -1.65 & 0.10 \\
\hline \multicolumn{6}{|c|}{ Hair } \\
\hline \multicolumn{6}{|c|}{ Exp-dose $\sim$ age $2+$ age $3+$ age $4+$ time-to-bleed + response } \\
\hline (Intercept) & 1.13 & 1.65 & 2.17 & 6.2 & 0.00 \\
\hline \multicolumn{6}{|l|}{ Factor(age) } \\
\hline Age 2 & -0.80 & -0.27 & 2.57 & -0.10 & 0.32 \\
\hline Age 3 & -0.96 & -0.34 & 2.73 & -1.08 & 0.28 \\
\hline Age 4 & -1.22 & -0.64 & -7.10 & -2.19 & 0.03 \\
\hline Time-to-bleed & -0.00 & -0.00 & 9.09 & -1.48 & 0.14 \\
\hline Response & -0.001 & 0.003 & 6.41 & 1.37 & 0.17 \\
\hline \multicolumn{6}{|c|}{ Faeces } \\
\hline \multicolumn{6}{|c|}{ Exp-dose $\sim$ age $2+$ age $3+$ age $4+$ time-to-bleed + age $1:$ response + age $2:$ respose + age $3:$ response + age $4:$ response } \\
\hline (Intercept) & 1.44 & 1.81 & 2.18 & 9.43 & 0.00 \\
\hline \multicolumn{6}{|l|}{ Factor (age) } \\
\hline Age 2 & -0.82 & -0.26 & 0.30 & -0.91 & 0.36 \\
\hline Age 3 & 0.50 & 1.12 & 1.74 & 3.53 & 0.00 \\
\hline Age 4 & -1.61 & -0.78 & 0.06 & -1.81 & 0.07 \\
\hline Time-to-bleed & -0.00 & -0.00 & -0.00 & -3.39 & 0.008 \\
\hline \multicolumn{6}{|l|}{ Response } \\
\hline Age 1: response & 0.003 & 0.008 & 0.01 & 3.28 & 0.001 \\
\hline Age 2: response & -0.00 & 0.01 & 0.01 & 1.49 & 0.14 \\
\hline Age 3: response & -0.01 & -0.00 & 0.00 & -1.16 & 0.25 \\
\hline Age 4: response & -0.01 & 0.01 & 0.03 & 1.24 & 0.21 \\
\hline
\end{tabular}

exposure dose at 18 time points, which corresponded to when samples were collected over the five-year project. The median exposure dose for an individual animal was then estimated using a discrete uniform distribution function ${ }^{16}$ that incorporated only the exposure doses for the months relevant to the period the animal was in the trial. The output was a distribution function of the dose ( $\mathrm{mg}$ vanadium per kilogram body weight per day) that individual animals would have been exposed to while they were in the trial. The median of this distribution function was then used as the predictor variable for the correlation analysis. Slaughter animals fell into one of nine groups of exposure, which were designated A to I (Table 7). It must be noted that the exposure dose calculated by the model includes intake from both oral and inhalation routes. A median of the output distribution function was used because the input environmental data was not normally distributed.

(3) The dose of vanadium that animals were being exposed to around the time of slaughter (end-dose). This was taken as the median dose in $\mathrm{mg}$ vanadium per $\mathrm{kg}$ body weight per day that was simulated by the model using the environmental inputs at the time closest to slaughter (Table 4).

\section{Ethics}

Prior to commencing the project, the protocol was reviewed and approved by the Animal Use and Care Committee of the Faculty of Veterinary Science and the ethics committee of the Faculty of Medicine, University of Pretoria, Pretoria, and registered as project no. 36.5.381. Sampling of animals was carried out by or under the supervision of registered veterinarians and all procedures were either routine farm management procedures or procedures which a South African registered veterinarian may carry out in the course of general large animal practice.

\section{Results}

Table 1 shows the average responses and normal ranges of the clinical chemistry parameters over the duration of the trial. It 
also gives the results of the confidence intervals for the differences between the HE and LE groups with respect to the clinical chemistry parameters. The normal ranges are those used at the Clinical Pathology Laboratory, Faculty of Veterinary Science, University of Pretoria, except for the protein fractions, which are those reported by Tumbleson et al. ${ }^{18}$ There were 24 observations over the five year period. From the table it can be seen that the HE group had significantly $(\alpha<0.05)$ lower Alb levels than the LE group. This is further reflected in the $\mathrm{A}: \mathrm{G}$ ratios, which were also lower in the HE group. Despite the Alb levels being lower in the HE group they were still within the lower normal range for cattle. None of the other clinical chemistry parameters showed evidence of a difference between exposure groups. The mean Glob, and in particular the $\beta$-glob fraction, and CK levels of both groups were above what is considered normal for cattle.

Table 2 shows the average cell counts or responses of the haematology parameters over the duration of the trial. Normal ranges are also given. There were 24 observations over the five-year period. Monocyte numbers and thrombocyte counts were significantly higher in the HE cattle than the LE cattle. The mean WCC were above the normal ranges for both groups.

Table 3 shows the average concentrations of vanadium in tissues and body fluids taken from live animals. The number of observations for each parameter is shown in the table. The variability in the number of observations is due to the difficulty in obtaining samples on occasion, the decision that rib-biopsies would have to be taken as a replacement for coccygeal vertebrae and the late realisation that hair may be a good biomarker and should be included. Concentrations of vanadium in the hair and faeces were found to be higher in cattle from the HE group than the LE group. Normal concentrations of vanadium in milk are given as $0-6 \mu \mathrm{g} \mathrm{kg}^{-1}$ (mean $=1$ $\left.\mu \mathrm{g} \mathrm{kg}^{-1}\right),{ }^{19}$ hence milk concentrations of vanadium are much higher than normal in both groups. Normal concentrations of vanadium in hair, urine, faeces and bone of cattle could not be found. Normal tissue levels in general foodstuffs do not usually exceed $1 \mathrm{mg} \mathrm{kg}^{-1}$, ${ }^{20}$ so the levels in these tissues are probably higher than what is considered normal.

Table 4 shows the exposure doses calculated for adult cattle at the 18 time periods when samples were taken. It also shows the exposure dose at the time when animals were slaughtered (end-dose). The exposure dose for the HE cattle was approximately twice that of the LE cattle.

Table 5 shows the results of the linear mixed effects meanexposure-dose model for parameters that differed significantly between the HE and LE groups (Tables 1, 2 and 3). It includes the effects of age group, duration of exposure and biomarker response at the time of bleeding. Hence, if serum albumin is monitored, the biomarker model for determining exposure dose in 0 to $6 \mathrm{~m}$ old (group 1) calves is mean-exposure-dose $=$ $2.88-(0.03 \times$ albumin response), while for 7 to $12 \mathrm{~m}$ old (group 2) calves mean-exposure-dose) would be $2.88-0.47-(0.03 \times$ albumin response).

Table 6 gives a summary of when the cattle were slaughtered, the number of cattle slaughtered, their sex and how many of these came from the HE area or LE area of the trial.
Table 7 gives a summary of the model outputs for the calculated median (50th percentile) exposure dose for the groups (A-I) that slaughter cattle fell into, depending on how long an individual animal had been in the trial. These values were also used as independent predictor variables for the correlations shown in Tables 10a and $b$.

Table 8 summarises the mean concentration of vanadium found in each tissue and the results of the lognormal distribution function simulation used to describe the range and probability of values occurring, given the variability in each set of data.

Table 9 shows the results of the Kruskall-Wallis multiple comparison tests for differences between the mean concentrations of vanadium in the various tissues. It also ranks the tissues from highest to lowest concentration of vanadium based on the median concentration of vanadium found in the tissue. Tissues can be grouped according to the amount of vanadium found in the tissue.

Tables 10a and $\mathrm{b}$ give the results of Spearman rank correlation between the median exposure-dose (Table 7), the number of days exposed, the end point exposure dose at the time of slaughter and the concentration of vanadium in the various tissues sampled.

Table 11 gives the results of the Spearman rank correlations between various bone samples, correlations between muscle groups and correlations between brain tissues.

\section{Discussion}

\section{Biomarkers in live cattle}

The TSP changes and those of its Alb and Glob fractions were similar to what was described previously in field outbreaks of chronic vanadium poisoning and further discussion of the chemical pathology and haematological changes is given in a previous paper. ${ }^{15}$ It has been postulated that the lowering of serum Alb levels may be related to a malabsorption syndrome that develops in calves exposed to vanadium. Whether the malabsorption is due to purely physical small intestinal changes or due to biochemical changes or both is uncertain. This work has been able to show that an inverse relationship exists between exposure dose and serum Alb (Table 5), and therefore Alb could be used as a measure of exposure. The best fitting model was without the interaction of age group, indicating that the dose: response relationship was the same for all age groups. The disadvantage of using Alb is that it

Table 6 Slaughter dates, exposure group, number and sex of sentinel cattle slaughtered in South Africa on the date shown

\begin{tabular}{lcccc}
\hline Date of slaughter & $\begin{array}{c}\text { No. from } \\
\text { HE camp }\end{array}$ & $\begin{array}{c}\text { No. from } \\
\text { LE camp }\end{array}$ & Male & Female \\
\hline 25-Aug-99 & 0 & 3 & 0 & 3 \\
09-Feb-01 & 5 & 2 & 3 & 4 \\
06-Mar-01 & 0 & 10 & 3 & 7 \\
31-May-02 & 2 & 6 & 7 & 1 \\
20-Jun-03 & 0 & 8 & 4 & 4 \\
07-May-04 & 3 & 3 & 6 & 0 \\
Total & 10 & 32 & 23 & 19 \\
HE = High exposure; & LE = Low exposure. \\
\hline
\end{tabular}


Table 7 Model outputs for the nine median dose groups of vanadium that slaughter cattle from a South African sentinel herd were exposed to depending on how long they were in the trial ${ }^{l}$

\begin{tabular}{|c|c|c|c|c|c|c|c|c|c|}
\hline Model output parameter & $\begin{array}{l}\text { A } \\
\text { LE }\end{array}$ & $\begin{array}{l}\text { B } \\
\text { HE }\end{array}$ & $\begin{array}{l}\mathrm{C} \\
\mathrm{LE}\end{array}$ & $\begin{array}{l}\text { D } \\
\text { HE }\end{array}$ & $\begin{array}{l}\text { E } \\
\text { LE }\end{array}$ & $\begin{array}{l}\mathrm{F} \\
\mathrm{LE}\end{array}$ & $\begin{array}{l}\mathrm{G} \\
\mathrm{LE}\end{array}$ & $\begin{array}{l}\mathrm{H} \\
\mathrm{HE}\end{array}$ & $\begin{array}{l}\text { I } \\
\text { LE }\end{array}$ \\
\hline Total V per day/mg d ${ }^{-1}$ & 552 & 1089 & 610 & 1506 & 606 & 510 & 571 & 1370 & 667 \\
\hline $\operatorname{Min} / \mathrm{mg} \mathrm{kg}^{-1} \mathrm{~d}^{-1}$ & 0.22 & 0.08 & 0.13 & 0.12 & 0.13 & 0.11 & 0.05 & 0.11 & 0.09 \\
\hline 5th percentile $/ \mathrm{mg} \mathrm{kg}^{-1} \mathrm{~d}^{-1}$ & 0.53 & 0.38 & 0.36 & 0.69 & 0.35 & 0.31 & 0.31 & 0.43 & 0.31 \\
\hline 50th percentile $/ \mathrm{mg} \mathrm{kg}^{-1} \mathrm{~d}^{-1}$ & 1.18 & 1.97 & 1.03 & 2.47 & 1.03 & 0.83 & 1.03 & 1.73 & 1.1 \\
\hline 95th percentile $/ \mathrm{mg} \mathrm{kg}^{-1} \mathrm{~d}^{-1}$ & 2.45 & 6.22 & 3.36 & 7.46 & 3.31 & 2.64 & 3.12 & 7.16 & 3.31 \\
\hline $\operatorname{Max} / \mathrm{mg} \mathrm{kg}^{-1} \mathrm{~d}^{-1}$ & 6.36 & 27.24 & 9.21 & 32.56 & 9.7 & 9.15 & 10.67 & 80.47 & 15.35 \\
\hline
\end{tabular}

requires an invasive process and levels of albumin can be influenced by other disease syndromes such as helminth infestation, protein loosing enteropathies, malabsorption, malnutrition and chronic liver disease, and it is thus not specific for vanadium. The elevated $\beta$-glob fraction is thought to be a result of increased transferrin, which is one of the components of $\beta$-glob. ${ }^{22}$ Both albumin and transferrin play a role in transporting the vanadate form of vanadium in plasma. ${ }^{23}$ A low Alb and high $\beta$-glob fraction is consistent with vanadium exposure in cattle.

Although the monocyte counts were within the normal range, the difference in monocyte numbers between the $\mathrm{HE}$ and LE cattle is interesting, as increased monocyte counts have been reported previously with chronic vanadium poisoning. ${ }^{15}$ They are derived from bone-marrow and circulate briefly in the blood before being transformed into macrophages. Their increase in this case may be related to phagocytosis and digestion of foreign particulate matter, like dust entering the lungs. However, independent studies at the mine showed that dust levels in the LE camp were higher than the HE camp ${ }^{24}$ and were classified by these authors as "slight" (i.e. $<250 \mathrm{mg}$ $\mathrm{m}^{-2} \mathrm{~d}^{-1}$ ) for both camps. Dust levels therefore, do not support the monocyte difference between the HE and LE cattle. The other possibility is their relationship to macrophage produc- tion of transferrin, ${ }^{22}$ which ties in with the concurrent increase in $\beta$-globulins, and is thus the more likely explanation. From these findings it therefore seems that a closer look at transferrin concentrations should be made to see what its relationship to vanadium exposure is. Transferrin may prove to be a better and more sensitive biomarker for vanadium exposure than $\beta$-glob fractions or monocyte counts. A linear mixed-effects model for monocytes is given in Table 5, but because raised monocyte counts are not specific for vanadium it is doubtful if the model could be used on its own as a predictor of exposure.

AG ratios were not considered for a linear mixed-effects model because the ratio is directly related to Alb concentrations, which was already being modelled. No difference could be shown between groups with respect to Glob concentrations (Table 1).

The raised CK levels are also a consistent finding with vanadium exposure and may be related to its role in catalyzing the transfer of a high energy phosphate bond from adenosine triphosphate (ATP) to creatine in resting muscle and the reverse when muscle contracts. ${ }^{22}$ Vanadium is known to interfere with energy transduction mechanisms, which suggest an effective participation of vanadium in the energetic coupling and transport of ATPases. ${ }^{23}$

Table 8 Concentrations of vanadium in tissue ( $\mathrm{mg} \mathrm{kg}^{-1}$ wet-weight basis) and milk of South African sentinel cattle (1999-2004) and results of the related lognormal simulation model

Model outputs

\begin{tabular}{|c|c|c|c|c|c|c|c|c|c|}
\hline \multirow[b]{3}{*}{ Tissue } & \multirow[b]{3}{*}{ Mean } & \multirow[b]{3}{*}{ Stdev } & \multicolumn{7}{|c|}{ Model outputs } \\
\hline & & & \multirow[b]{2}{*}{ Mean } & \multirow[b]{2}{*}{ Stdev } & \multirow[b]{2}{*}{ Min } & \multicolumn{3}{|c|}{ Percentiles } & \multirow[b]{2}{*}{ Max } \\
\hline & & & & & & 5 th & 50 th & 95 th & \\
\hline $\begin{array}{l}\text { Rumen } \\
\text { Mesenteric }\end{array}$ & 16.67 & 14.61 & 16.11 & 10.19 & 1.42 & 5.25 & 13.62 & 35.33 & 142.5 \\
\hline Lymphnode & 2.94 & 2.76 & 3.21 & 4.69 & 0.03 & 0.31 & 1.81 & 10.56 & 122.81 \\
\hline Liver & 2.79 & 2.96 & 2.72 & 3.29 & 0.04 & 0.36 & 1.72 & 8.29 & 68.64 \\
\hline Kidney & 1.94 & 1.57 & 1.94 & 1.79 & 0.07 & 0.39 & 1.42 & 5.19 & 28.31 \\
\hline Rib & 1.82 & 1.71 & 1.76 & 1.53 & 0.07 & 0.38 & 1.32 & 4.57 & 23.86 \\
\hline Spleen & 1.32 & 0.89 & 1.35 & 1.15 & 0.07 & 0.31 & 1.03 & 3.47 & 16.84 \\
\hline Tail-bone & 1.65 & 1.91 & 1.66 & 2.5 & 0.01 & 0.15 & 0.92 & 5.5 & 75.36 \\
\hline Rib-biopsy & 1.01 & 0.46 & 1.01 & 0.48 & 0.17 & 0.44 & 0.91 & 1.91 & 7.15 \\
\hline Lung & 1.4 & 1.35 & 1.5 & 2.26 & 0.01 & 0.14 & 0.83 & 4.94 & 76.12 \\
\hline Cerebellum & 0.8 & 0.76 & 0.83 & 1.22 & 0 & 0.08 & 0.47 & 2.75 & 27.58 \\
\hline Diaphragm & 0.75 & 0.76 & 0.8 & 1.32 & 0.01 & 0.06 & 0.42 & 2.74 & 44.32 \\
\hline Cerebrum & 0.78 & 0.83 & 0.88 & 1.78 & 0 & 0.05 & 0.38 & 3.21 & 49.75 \\
\hline Fillet & 0.86 & 0.99 & 0.96 & 2.19 & 0 & 0.04 & 0.37 & 3.59 & 68.38 \\
\hline Triceps & 0.61 & 0.63 & 0.61 & 0.87 & 0.01 & 0.06 & 0.35 & 2 & 18.23 \\
\hline Testes & 0.28 & 0.27 & 0.27 & 0.22 & 0.01 & 0.06 & 0.21 & 0.67 & 4.16 \\
\hline Milk & 0.39 & 0.46 & 0.47 & 1.09 & 0 & 0.02 & 0.18 & 1.75 & 45.79 \\
\hline Whole blood & 0.08 & 0.02 & 0.08 & 0.02 & 0.03 & 0.06 & 0.08 & 0.12 & 0.21 \\
\hline
\end{tabular}


Table 9 Results of the Kruskall-Wallis multiple-comparison test for differences between the median concentrations of vanadium in tissue of slaughtered South African sentinel cattle (1999-2004)

\begin{tabular}{|c|c|c|c|}
\hline Group & Count & Median & Different from groups \\
\hline Rumen & 39 & 13.00 & $\begin{array}{l}\text { Cerebrum, cerebellum, diaphragm, fillet, kidney, liver, lung, spleen, mesenteric lymphnode, } \\
\text { rib biopsy, rib, tail-bone, testes, triceps, whole blood }\end{array}$ \\
\hline Mesenteric lymphnode & 29 & 1.74 & Cerebellum, cerebrum, diaphragm, fillet, rumen content, testes, triceps, whole blood \\
\hline Spleen & 23 & 1.58 & Rumen content, testes, triceps, whole blood, \\
\hline Liver & 42 & 1.34 & Cerebellum, cerebrum, diaphragm, fillet, rumen content, testes, triceps, whole blood \\
\hline Rib & 39 & 1.10 & Cerebellum, cerebrum, diaphragm, fillet, rumen content, testes, triceps, whole blood \\
\hline Kidney & 42 & 1.10 & Cerebellum, cerebrum, diaphragm, fillet, rumen content, testes, triceps, whole blood \\
\hline Rib biopsy & 22 & 0.89 & Rumen content, testes, whole blood \\
\hline Lung & 42 & 0.84 & Rumen content, testes, whole blood \\
\hline Tail-bone & 42 & 0.67 & Rumen content, testes, triceps, whole blood \\
\hline Diaphragm & 42 & 0.36 & Cerebellum, kidney, liver, mesenteric lymphnode, rib, rumen content \\
\hline Cerebellum & 34 & 0.30 & Kidney, liver, mesenteric lymphnode, rumen content \\
\hline Fillet & 38 & 0.28 & Kidney, liver, mesenteric lymphnode, rib, rumen content \\
\hline Cerebrum & 39 & 0.27 & Kidney, liver, mesenteric lymphnode, rib, rumen content \\
\hline Triceps & 39 & 0.25 & Kidney, liver, spleen, mesenteric lymphnode, rib, rumen content, tail-bone \\
\hline Testes & 14 & 0.19 & Kidney, liver, lung, spleen, mesenteric lymphnode, rib biopsy, rib, rumen content, tail-bone \\
\hline Whole blood & 8 & 0.08 & Kidney, liver, lung, spleen, mesenteric lymphnode, rib biopsy, rib, rumen content, tail-bone \\
\hline
\end{tabular}

The higher than normal WCC, seen in these clinically healthy cattle, was also a consistent finding for chronic vanadium poisoning in calves. ${ }^{15}$ In vanadium poisoning, this was related to an increase in lymphocytes and immature neutrophils. ${ }^{15}$ No increase in neutrophils was seen in this study, although lymphocyte counts were in the upper normal range. It is thought that this response may be evidence of a chronic inflammation or immune stimulation taking place.

Why thrombocyte counts were higher in the HE animals is unknown and the link to vanadium cannot be explained. Since other confounding factors, such as splenic contraction, can increase $\mathrm{Thr} \mathrm{Cs}$, it was decided not to consider $\mathrm{Thr} \mathrm{Cs}$ as a useful biomarker for the time being. Further work needs to be done to explain a possible link between thrombocyte production and vanadium.

It can be argued that Alb, $\beta$-glob and monocyte counts are too non-specific to be used as biomarkers, however, Aldrich et al. ${ }^{1}$ advocate employing a suite or battery of appropriate biomarkers, particularly for long term exposures. It may therefore be possible to increase the specificity for detecting vanadium exposure by using the biomarker responses as a battery of tests in parallel. In the same way, the accuracy of predicting exposure doses can be potentially increased by combining the results of the regression models, given in Table 5 for these biomarkers, rather than use them on an individual basis.

The difference in vanadium concentrations of hair and faeces between the HE and LE groups (Table 3) and the relationship between vanadium concentrations in hair and faeces, and exposure doses (Table 5), highlights these tissues as potential biomarkers of vanadium exposure for cattle. These tissues are also easy samples to obtain and require non-invasive techniques. However, a lag phase probably exists between vanadium exposure and hair concentration that is

Table 10 (a) Correlation between exposure variables and various tissue concentrations of vanadium in South African sentinel cattle (1999-2004) using the Spearman rank test. (b) Correlation between exposure variables and various tissue concentrations of vanadium in South African cattle (1999-2004) using the Spearman rank test

(a)

\begin{tabular}{|c|c|c|c|c|c|c|c|c|c|c|}
\hline & $\begin{array}{l}\text { Median exposure } \\
\text { dose }\end{array}$ & Days exposed & $\begin{array}{l}\text { End exposure } \\
\text { dose }\end{array}$ & Lung & Liver & Kidney & Diaphragm & Fillet & Triceps & $\begin{array}{l}\text { Rumen } \\
\text { content }\end{array}$ \\
\hline$n$ & 42 & 42 & 42 & 42 & 42 & 42 & 42 & 38 & 39 & 39 \\
\hline Median exposure dose & 1.00 & -0.04 & 0.49 & 0.06 & 0.06 & 0.01 & 0.06 & -0.09 & 0.00 & -0.06 \\
\hline$P$-value & 0.00 & 0.80 & 0.00 & 0.69 & 0.69 & 0.93 & 0.71 & 0.61 & 0.99 & 0.74 \\
\hline Days exposed & -0.04 & 1.00 & 0.14 & 0.29 & 0.43 & 0.25 & 0.00 & 0.16 & 0.21 & 0.21 \\
\hline$P$-value & 0.80 & 0.00 & 0.39 & 0.06 & 0.00 & 0.11 & 0.98 & 0.33 & 0.20 & 0.21 \\
\hline End exposure dose & 0.49 & 0.14 & 1.00 & 0.51 & 0.66 & 0.52 & 0.61 & 0.53 & 0.55 & -0.08 \\
\hline$P$-value & 0.00 & 0.39 & 0.00 & 0.00 & 0.00 & 0.00 & 0.00 & 0.00 & 0.00 & 0.62 \\
\hline
\end{tabular}

(b)

\begin{tabular}{llllllllll}
\hline & Tail-bone & Rib & Rib biopsy & Cerebellum & Cerebrum & Mesenteric lymphnode & Spleen & Testes & Whole blood \\
\hline$n=$ & 42 & 39 & 22 & 34 & 39 & 29 & 23 & 14 & 8 \\
Median exposure dose & 0.04 & 0.10 & 0.48 & 0.06 & -0.05 & -0.05 & -0.45 & 0.58 & 0.25 \\
$P$-value & 0.81 & 0.53 & 0.02 & 0.73 & 0.76 & 0.80 & 0.03 & 0.03 & 0.55 \\
Days exposed & 0.26 & 0.01 & -0.18 & 0.25 & 0.15 & 0.32 & 0.43 & 0.30 & 0.24 \\
$P$-value & 0.09 & 0.95 & 0.42 & 0.15 & 0.36 & 0.09 & 0.04 & 0.30 & 0.57 \\
End exposure dose & 0.69 & 0.58 & 0.13 & 0.52 & 0.51 & 0.53 & 0.47 & 0.14 & 0.25 \\
$P$-value & 0.00 & 0.00 & 0.56 & 0.00 & 0.00 & 0.00 & 0.02 & 0.64 & 0.55 \\
\hline
\end{tabular}


Table 11 Correlations between muscle groups, between bone samples and between brain tissues of South African sentinel cattle (1999-2004) using the Spearman rank test

\begin{tabular}{|c|c|c|c|c|c|c|c|c|}
\hline & Fillet muscle & Triceps muscle & Diaphragm muscle & Tail-bone & Rib-bone & Rib biopsy & Cerebellum & Cerebrum \\
\hline$n$ & 38 & 39 & 42 & 22 & 39 & 22 & 34 & 39 \\
\hline Fillet muscle & 1.00 & 0.85 & 0.87 & & & & & \\
\hline$P$-value & 0.00 & 0.00 & 0.00 & & & & & \\
\hline Triceps muscle & 0.85 & 1.00 & 0.87 & & & & & \\
\hline$P$-value & 0.00 & 0.00 & 0.00 & & & & & \\
\hline Diaphragm muscle & 0.87 & 0.87 & 1.00 & & & & & \\
\hline$P$-value & 0.00 & 0.00 & 0.00 & & & & & \\
\hline Tail-bone & & & & 1.00 & 0.76 & 0.38 & & \\
\hline$P$-value & & & & 0.00 & 0.00 & 0.08 & & \\
\hline Rib-bone & & & & 0.76 & 1.00 & 0.67 & & \\
\hline$P$-value & & & & 0.00 & 0.00 & 0.00 & & \\
\hline Rib biopsy & & & & 0.38 & 0.67 & 1.00 & & \\
\hline$P$-value & & & & 0.08 & 0.00 & 0.00 & & \\
\hline Cerebellum & & & & & & & 1.00 & 0.81 \\
\hline$P$-value & & & & & & & 0.00 & 0.00 \\
\hline Cerebrum & & & & & & & 0.81 & 1.00 \\
\hline$P$-value & & & & & & & 0.00 & 0.00 \\
\hline
\end{tabular}

related to the rate of hair growth and further work needs to be done to try and model this. The use of hair as a biomarker has long been recognised ${ }^{25}$ and there have been a number of studies in animals that have shown that hair can be used as indicators of mineral status or as biomarkers for metal airpollutants. ${ }^{26-28}$ However, few studies appear to have been done with respect to vanadium. ${ }^{29}$ Users of hair as biomarkers need to be aware of some of the issues surrounding the collection of samples and the analytic techniques used for the determination of vanadium ${ }^{30,31}$ as well as take into account confounding factors such as contaminants on the hair, hair growth stage and age of cattle when comparing results with other studies. ${ }^{27}$

The use of faeces as a biomarker is also not a new idea but no other faecal biomarker studies for vanadium appear to have been done in ruminants. It appears that some vanadium, in the form of soil may accumulate in the rumen of exposed cattle due to normal animal behaviour, and this could take some time to be excreted, ${ }^{32}$ how this affects the relationship between exposure and faecal vanadium concentrations is yet to be determined, but there could be a lag phase between ingestion and faecal excretion. The other interesting finding that came out of the mixed-effect model was that age group played a role in predicting the exposure dose (Table 5); it is uncertain why this should be the case but it may be related to rumen development.

\section{Concentration of vanadium in tissue}

The concentrations of vanadium shown in Table 8 are for cattle that were clinically normal. All their carcasses passed meat inspection, were considered fit for human consumption and showed no obvious macroscopic pathology of any significance. These concentrations far exceed what is considered normal by Puls ${ }^{19}$ and also exceeds what others consider as the range of vanadium concentrations that is typical for foodstuffs. $^{20,23,25}$ In fact without a history, the concentration of vanadium in these tissues would be consistent with what is reported for ruminants that are suffering from clinical signs of vanadium poisoning. ${ }^{15,33}$ Of concern therefore, is the assump- tion that is often made by veterinarians or environmentalists that a particular concentration of vanadium in tissue is consistent with vanadium poisoning. What becomes apparent when looking at the results of this study and what is reflected in the tissue lognormal models (Table 8 ) is the variability that is seen with respect to vanadium tissue concentrations. Also apparent is the fact that adult cattle can have relatively high concentrations of vanadium in their tissues without apparent ill-effect. Using tissue levels as a diagnostic tool for toxicity therefore, needs to be done with caution. This study has however confirmed that higher than normal tissues levels are consistent with vanadium exposure and can be used as a type 1 category biomarker. ${ }^{1}$ Frank et $a l .{ }^{33}$ reported similar findings in Swedish cattle suffering from vanadium poisoning after grazing on pastures fertilized with basic slag containing vanadium. The public health implications of high tissue levels have been discussed in a previous paper. ${ }^{21}$

According to Nriagu, ${ }^{23}$ experiments with animals support a retention order for vanadium of: bone $>$ kidney $>$ liver $>$ spleen $>$ bowel $>$ stomach $>$ blood $>$ lung $>$ brain, with another retention site being the testes. Examination of Table 8 shows a retention order for the cattle in this trial, based on predicted median (fifty percentile) concentrations of vanadium, to be rumen $>$ mesenteric lymphnode $>$ spleen $>$ liver $>$ rib-bone $>$ kidney $>$ lung $>$ tail-bone $>$ diaphragm $>$ cerebellum $>$ fillet $>$ cerebrum $>$ triceps $>$ testes $>$ whole blood.

For the retention order to be meaningful it was necessary to see if there was a significant difference in vanadium concentration between tissues. It was possible from the results (Table 9) to group the retention of vanadium in tissues into three categories, high, middle and low. The first category is the rumen content, which was significantly higher in vanadium than any of the other tissues monitored. This is understandable given that the bulk of the vanadium is taken in by cattle via the oral route and only a relatively small percentage of this vanadium is thought to be available for absorption. In this study vanadium concentrations in the rumen were 7.5 times greater than in the mesenteric lymphnodes, which had the highest tissue concentrations (Table 8 model median values). 
The second category comprises the mesenteric lymphnodes, liver, bone, kidney, lung and spleen. Vanadium may target the immune system, ${ }^{15}$ which could explain the high concentrations in lymphnodes, bone (marrow) and spleen. In addition, vanadium ions probably have a profound influence on metabolic processes involving calcium, and recent studies suggest bone and connective tissue as target sites for vanadium biological actions, ${ }^{23}$ hence the high levels found in bone. The levels of vanadium in bone are not significantly different from other tissues in this category (Table 9) and despite the long duration of exposure, there is no evidence that vanadium accumulates in bone, as has often been reported. ${ }^{34}$ The lung, like the rumen is a route for vanadium absorption and the liver and kidneys are excretory organs, which may explain why they are high in vanadium. The high concentrations in the liver are also partly explained by the fact that vanadium is thought to be specially stored in organs rich in ferritin, which is found in high concentrations in the liver. ${ }^{23}$ It is interesting that $\mathrm{Nriagu}^{23}$ placed lungs far lower in his order of retention and this may be a function of exposure rather than retention.

The third category comprises brain, muscle, testes and blood. The relevance of vanadium concentrations in the brain is related to the nervous symptoms that can occur with vanadium exposure. ${ }^{33}$ There is increasing evidence to suggest that these symptoms are related to biochemical synapse changes rather than physical damage, yet there does not appear to be any accumulation of vanadium in the central nervous system. Similarly, there do not appear to be high levels in the testes despite some authors referring to the testes as a retention site. ${ }^{23}$

Given the variability of concentrations of vanadium in tissues (Table 8), it is unlikely that one can be more precise in the retention order of vanadium than these three categories. What distinguishes this study from other studies is the long duration over which these cattle were exposed.

\section{The relationship between tissue concentrations and exposure}

One of the primary purposes of the cattle trial was to study the merits of using cattle as sentinels within the vanadium mining industry. The question that therefore arose was what was the value of tissue levels of vanadium in assessing environmental exposure to vanadium? Particularly because tissues can be easily obtained from cattle sent to abattoirs for slaughter. Diaphragm was sampled because it was a tissue that could be easily obtained on the slaughter line without reducing the value of the carcass. Rib-biopsies and tail-bones were taken because they were alternative bone tissues that could be sampled on farm from living animals if necessary. Tables $10 \mathrm{a}$ and $\mathrm{b}$ show that there was no correlation between the time an animal was in the trial and the tissue concentrations. This supports evidence that vanadium is non accumulative and has a fairly rapid excretion rate. ${ }^{35}$ This is further supported by the fact that there is also no correlation between the median exposure dose and tissue concentrations. The relationship between the end-dose and tissue concentrations is more difficult to interpret. Tables $10 \mathrm{a}$ and $\mathrm{b}$ show that there is a significant $(\alpha=0.05)$ and moderate correlation between the end-dose and concentrations of vanadium in the tail-bone, diaphragm, liver and rib-bone in descending order of magnitude. It must be noted however that although there are positive correlations between exposure and vanadium concentrations in these tissues, the relationship is not necessarily linear, which would explain why similar concentrations of vanadium can be found in organs from poisoned animals as well as healthy animals farmed in areas just below the noadverse-effect-level. For most other tissues, correlations with the end-dose were statistically significant but weak. Rumen content, testes, whole blood and rib-biopsies had no correlation to end-dose. The lack of correlation to whole blood and testes may be due to the smaller number of samples taken for these tissues. What was surprising was the lack of correlation between exposure dose and rumen content, which could suggest the accumulation of vanadium in the rumen over time. There was a good correlation between the tail-bone and ribbone (Table 11), making the tail-bone a reliable indicator of bone concentrations. However, the correlation between the rib-biopsies and rib-bone and tail-bone were poor, making ribbiopsies a questionable means of assessing bone concentrations of vanadium. This is probably due to the small weight of bone sample obtained with a biopsy. The correlation of vanadium concentrations between the diaphragm and the fillet and triceps muscles was good, thus making the diaphragm a reliable substitute for more expensive muscle cuts when sampling a carcass for public health reasons.

\section{Conclusions}

Despite the wide range of potential biomarkers screened in this study, no ideal biomarker has emerged. Urine is not a good biomarker. Hair and faeces are better non-invasive biomarkers for cattle. Serum albumin levels and monocyte counts are correlated to vanadium exposure and a concurrent decrease in albumin and increase in monocyte counts may be a useful tool for monitoring changes in exposure over time. Raised monocyte counts and $\beta$-glob may be linked to transferrin production, which could prove to be a better biomarker. Tissue levels of vanadium in healthy cattle include a much wider range than is currently reflected in the literature. The best tissue from slaughter animals for assessing vanadium exposure is probably the liver, which had concentrations that were moderately correlated to exposure doses of vanadium.

\section{Acknowledgements}

The authors would like to thank the following people for their various inputs into the project, Sr. I. de Goede, Mr. L. Ford, Dr D. Holm, Mr. P. Kruger, Dr W. Schultheiss, Mr. D. Stein, Mr. J. J. van der Merwe.

\section{References}

1 T. Aldrich, J. Griffith and C. Cookie, Environmental Epidemiology and Risk Assessment, Van Nostrand Reinhold, New York, 1993.

2 NRC, Biological markers in pulmonary toxicology, National Academy Press, Washington, DC, 1989a.

3 NRC, Biological markers in pulmonary toxicology, National Academy Press, Washington, DC, 1989b. 
4 B. Gylseth, H. L. Leira, E. Steiness and Y. Thomassen, Vanadium in blood and urine of workers in a ferroalloy plant, Scand. J. Work Environ. Health, 1979, 5, 188-194.

5 M. Kiviluoto, L. Pyy and A. Pakarinen, Serum and urinary vanadium of workers processing vanadium pentoxide, Int. Arch. Occup. Environ. Health, 1981, 48, 251-256.

6 C. E. Lewis, The biological effects of vanadium. II. The signs and symptoms of occupational vanadium exposure, AMA Arch. Ind. Health, 1959, 19, 497-503.

7 P. Orris, J. Cone and S. McQuilkin, Health hazard evaluation report HETA 80-096-1359, Eureka Company, Bloomington, IL, Washington, DC, US Department of Health and Human Services, National Institute of Occupational Safety and Health, NTISPB85-163574, 1983.

8 C. Zenz, J. P. Bartlett and W. H. Thiede, Acute vanadium pentoxide exposure, Arch. Environ. Health, 1962, 14, 542-546.

9 USEPA Standard Methods, Method 3050 Acid digestion of sediments, sludges and soils, Test methods for evaluating solid waste, physical/chemical methods ( $S W$-846), USA Environmental Protection Agency, Washington, DC, 1986.

10 Handbook of standard soil testing methods for advisory purposes, Soil Science Society of South Africa, Pretoria, Republic of South Africa, 1990.

11 USEPA Standard Methods, Method 3052 Microwave assisted acid digestion of siliceous and organically based matrices, Test methods for evaluating solid waste, physical/chemical methods ( $S W$-846), Environmental Protection Agency, Washington, DC, 1996.

12 B. Gummow, W. F. A. Kirsten, R. J. Gummow and J. A. P. Heesterbeek, A stochastic exposure assessment model for estimating intake of vanadium by beef cattle used as sentinels within the South African vanadium mining industry, Prev. Vet. Med., 2006, in press.

13 J. Hintze, NCSS and PASS Number Cruncher Statistical Systems, NCSS, Kaysville, UT, 2001, www.NCSS.com.

14 R Development Core Team, R Foundation for Statistical Computing, Vienna, Austria, 2004, http:/www.R-project.org, ISBN 3900051-00-3.

15 B. Gummow, S. S. Bastianello, C. J. Botha, H. J. C. Smith, A. J. Basson and B. Wells, Vanadium air pollution: a cause of malabsorption and immunosuppression in cattle, Onderstepoort J. Vet. Res., 1994, 61, 303-316.

16 David Vose, ModelAssist for@Risk, Risk Thinking, Ltd, UK, version 1.0, 2004, http://www.risk-modelling.com.

17 (a) O. J. Dunn, Multiple comparisons using rank sums, Technometrics, 1964, 6, 241-252; (b) J. Gibbons, Nonparametric Methods for Quantitative Analysis, Holt, Rinehart and Winston, New York, 1976.

18 M. E. Tumbleson, M. F. Burkes and W. E. Wingfield, Serum protein concentrations, as a function of age, in female dairy cattle, Cornell Vet., 1973, 63, 65-71.

19 R. Puls, Mineral levels in animal health: Diagnostic data, Sherpa International, Clearbrook, BC, Canada, 1988.
20 Toxicological Profile for Vanadium, US Department of Health \& Human Services, Public Health Service, Agency for Toxic Substances and Disease Registry, TP-91/29, 1992.

21 B. Gummow, C. J. Botha, J. P. T. M. Noordhuizen and J. A. P. Heesterbeek, The public health implications of farming cattle in areas with high background concentrations of vanadium, Prev. Vet. Med., 2005, 72, 281-290.

22 J. R. Duncan and K. W. Prasse, Veterinary Laboratory Medicine, Iowa State University Press, Ames, IA, 1986.

23 J. O. Nriagu, Vanadium in the Environment, John Wiley \& Sons, Inc., New York, 1998.

24 L. W. Burger and R. M. Watson, Air quality impact assessment for Xstrata Rhovan vanadium smelter, Report No. EMS/03/XST-01 Rev 2, Environmental Management Services cc, Wierda Park, South Africa, 2003.

25 C. Reilly, Metal contamination of food, Elsevier Applied Science, London, 2nd edn, 1991.

26 D. K. Combs, R. D. Goodrich and J. C. Meiske, Mineral concentrations in hair as indicators of mineral status: A Review, J. Anim. Sci., 1982, 54(2), 391-398.

27 C. Ronneau, M. Detry, P. H. Hallet and P. Lardinois, Concentration of some elements in the hair of cattle as an indicator of contamination by air pollutant deposition on grass, Agric., Ecosyst. Environ., 1983, 10, 285-298.

28 D. D. Fisher, L. L. Wilson, R. M. Leach and R. W. Scholz, Switch hair as an indicator of magnesium and copper status of beef cattle, Am. J. Vet. Res., 1985, 46(11), 2235-2240.

29 US Department of Health \& Human Services, Toxicological Profile for Vanadium, Public Health Service, Agency for Toxic Substances and Disease Registry, TP-91/29, 1992.

30 S. Seidel, R. Kreutzer, D. Smith, S. McNeel and D. Gilliss, Assessment of commercial laboratories performing hair mineral analysis, J. Am. Med. Assoc., 2001, 285(1), 67-72.

31 S. J. Steindel and P. J. Howanitz, The uncertainty of hair analysis for trace metals, J. Am. Med. Assoc., 2001, 285(1), 83-85.

32 B. Gummow, Vanadium Mining and Cattle Health: Sentinel studies, epidemiological and veterinary public health issues, $\mathrm{PhD}$ thesis, University of Utrecht, Utrecht, Netherlands, 2005.

33 A. Frank, A. Madej, V. Galgan and L. R. Petersson, Vanadium poisoning of cattle with basic slag, Concentrations in tissues from poisoned animals and from a reference, slaughter-house material, Sci. Total Environ., 1996, 181, 73-92.

34 Concise International Chemical Assessment Document (CICAD), Vanadium pentoxide and other inorganic vanadium compounds, Document number 29, International Programme on Chemical Safety, INCHEM, World Health Organisation, Geneva, 2001, http://www.inchem.org/documents/cicads/cicads/cicad29. htm.

35 B. W. Patterson, S. L. Hansard, C. B. Ammerman, P. R. Henry, L. A. Zech and W. R. Fisher, Kinetic model of whole vanadium metabolism: studies in sheep, Am. J. Physiol., 1986, 251, R325-R332. 